\title{
A MEMÓRIA FOTOGRÁFICA DE HOLLYWOOD EM MADUREIRA: EDITANDO POSES E FLAGRANTES DA BAILARINA DO MORRO DA FAVELA NO CONTEXTO DA "POLÍTICA DA BOA VIZINHANÇA".
}

\author{
Sormani da Silva ${ }^{1}$
}

\begin{abstract}
Resumo: O objetivo deste artigo é abordar o arquivo fotográfico como artefato de memória. A fotografia em questão, denominada como bailarina do Morro da Favela, foi produzida pela Divisão de Turismo do DIP (Departamento de Imprensa e Propaganda) durante a passagem de Walt Disney pelo Brasil em agosto de 1941. A proposta de uma memória fotográfica, se articula num processo em que a percepção da imagem transita entre a noção de arte e testemunho dos acontecimentos. Ao mesmo tempo o artigo insere uma discussão sobre a emergência das escolas de samba no âmbito das relações culturais, e com isso, problematizando através da imagem, as contradições da política de turismo no contexto da "Política da Boa Vizinhança".
\end{abstract}

Palavras Chave: fotografia, escola de samba, relações culturais, memória, turismo

\section{THE PHOTOGRAPHIC MEMORY OF HOLLYWOOD IN MADUREIRA: EDITING POSES AND FLAGRANTE OFTHE DANCER OFTHE SLUM HILL INTHE CON- TEXT OFTHE "GOOD NEIGHBOR POLICY.}

\begin{abstract}
The purpose of this article is to approach the photographic archive as a memory artifact. The photograph in question, named as a dancer from Morro da Favela, was produced by the Tourism Division of DIP (Department of Press and Propaganda) during Walt Disney's visit to Brazil in August 1941. The proposal for a photographic memory articulates in a process in which the perception of the image transits between the notion of art and witness of events. At the same time, the article inserts a discussion about the emergence of samba schools in the context of cultural relations, and with this, through the image, problematizes the contradictions of tourism policy in the context of the "Good Neighbor Policy".
\end{abstract}

Keywords: photography, samba school, cultural relations, memory, tourism

${ }^{1}$ Doutorando em Memória Social na Unirio - sormanisil@outlook.com 

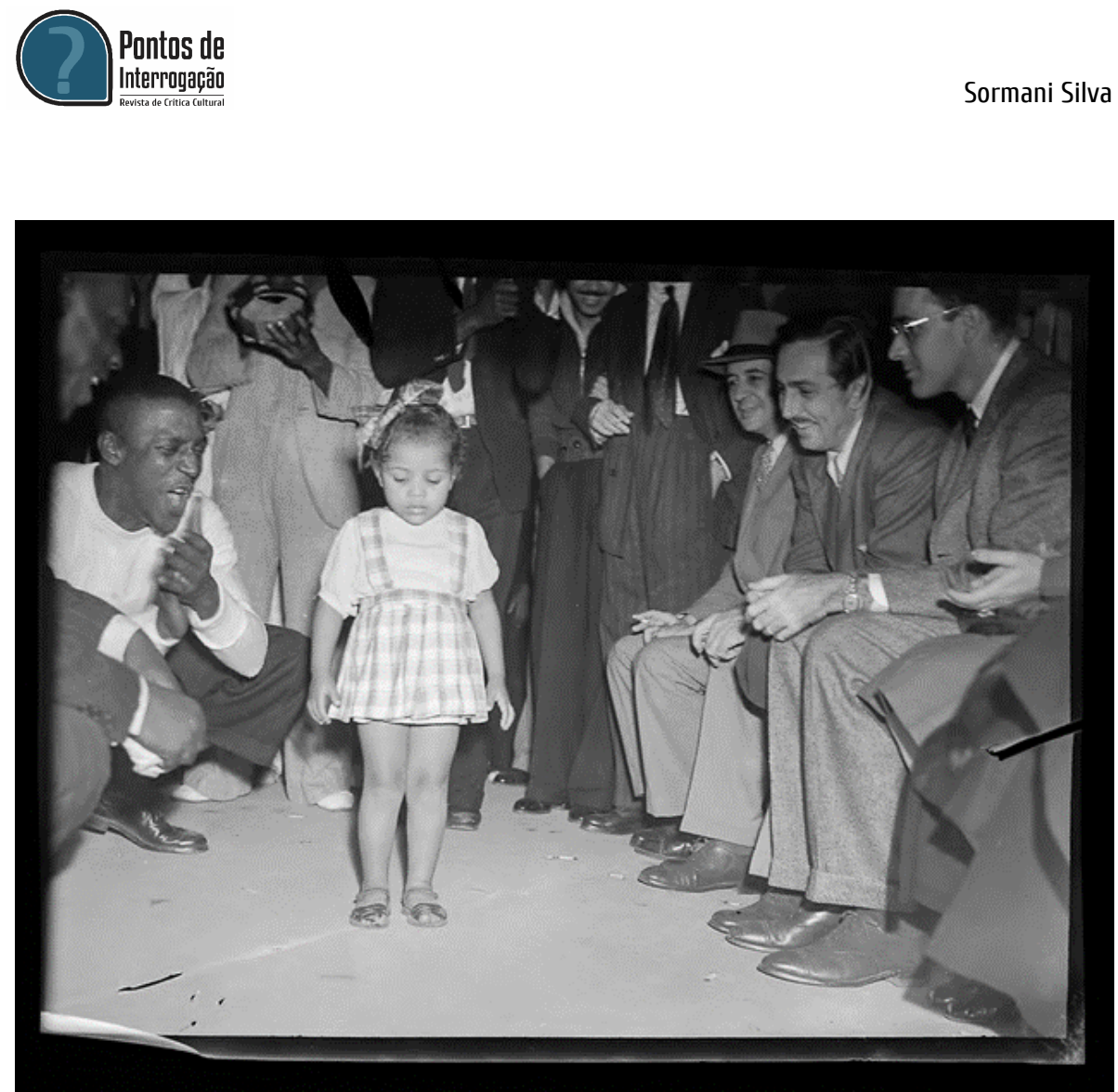

Fig. 1. Setor de Fundos e coleções: Arquivo Nacional Imagem da bailarina do morro da Favela, ou morro da Portela ${ }^{2}$

\section{Uma digressão sobre a fotografia:}

A noite de batucada organizada para a visita de Walt Disney possibilitou a produção de um rico conjunto de imagens, atualmente composto por 10 fotografias em preto e branco, e todas foram produzidas no período noturno, se restringindo ao ambiente interno da escola de samba Portela, em agosto de 1941. Mas a história desses arquivos é longa. A imagem que temos acima (fig.1) é derivada dos negativos que sobreviveram à poeira do tempo, e do risco de perda nos arquivos. Depois de anos sob a reponsabilidade, em condições precárias, nas instalações da Polícia Federal no Rio de Janeiro. Parte deste acervo que estava sob a guarda da antiga Agência Nacional, com a

\footnotetext{
${ }^{2}$ A fotografia foi publicada nos jornais: Correio da Manhã, Rio de Janeiro de 26 de agosto de 1941 p.13, O imparcial, Rio de Janeiro de 26 agosto de 1941 p.5, Diário Carioca, Rio de Janeiro, 18 de janeiro de 1946 p.8.

O Jornal, Rio de Janeiro 26 de agosto de 1941 p.10.
} 
A MEMÓRIA FOTOGRÁFICA DE HOLLYWOOD EM MADUREIRA: EDITANDO POSES E

extinção do DIP (Departamento de Imprensa e Propaganda), foram cedidos ao Arquivo Nacional, que o reclassificou e recentemente disponibilizou como fonte. Atualmente tais documentos foram contemplados, em conjunto com outros documentos do Arquivo Nacional, dentro do projeto da Unesco denominado "Memória Mundo", aspecto que o torna mais representativo.

A fotografia em questão (fig.1) foi a que mais se destacou desse dossiê produzindo pela Divisão de Turismo, cuja função era produzir e distribuir as fotografias. Assim, a imagem circulou pelos diversos jornais na época, e a encontramos também no livro Imperialismo Sedutor do historiador Antônio Pedro Tota. Infelizmente não temos, até o momento, a informação definitiva sobre o fotografo responsável pela produção do arquivo ${ }^{3}$. O mesmo pode ser tanto obra de um fotografo brasileiro, como estrangeiro. Nesta época atuavam nos quadros funcionais do DIP diversos fotógrafos estrangeiros. Um exemplo que temos, e que por sinal está registrado neste artigo, (Fig.2) foi a atuação de Jean Manzon. O fotografo francês estava presente na comitiva da Divisão de Turismo que acompanhou a visita de Walt Disney. Na oportunidade ele apresentou para Disney na ABI (Associação Brasileira de Imprensa) uma parte de seu trabalho fotográfico no Brasil denominado: Exposição de Reportagens Fotográficas, que provavelmente era resultado de sua atuação como diretor de cinema e fotografia, cargo que exerceu entre 1940 e 1943, antes de ser contratado pela revista $O$ Cruzeiro. Sendo assim existe uma boa hipótese de que Jean Manzon tenha participado da equipe de fotógrafos, ou mesmo auxiliado na produção da memória fotográfica desta noite histórica de Disney em Madureira. O estilo de preparação da cena, com poses para a produção da fotografia, elementos que encontramos facilmente nos trabalhos do fotografo francês, é identificável na imagem, todavia os registros oficiais da agência nacional não identificam o seu autor.

Nesta época as fotografias produzidas pelo DIP passaram a ter uma abordagem para além do sentido meramente informativo. A adoção de maquinas mais modernas permitiu que os fotógrafos inserissem em suas produções o registro de movimentos, poses e espaços. Segundo MAUAD (2017) a composição do espaço fotográfico está intimamente vinculada ao equipamento utilizado por esses profissionais. Essas disponibilidades técnicas

3 Não é objetivo do artigo estabelecer uma discussão sobre a autoria da fotografia neste momento da pesquisa. 
permitiram um campo de atuação muito importante através da consolidação do fotojornalismo, enfatizando o sentido de verossimilhança, que a imagem carrega na sedução do olhar. Articulando um princípio estético em que os cenários também seriam inseridos, artística e tecnicamente pela destreza dos fotógrafos promovendo as suas montagens. Assim constatamos na fotografia (fig. 1) o sentido profundidade, além do jogo de luzes capazes de transformar o chão da agremiação em um palco de apresentação, o que comprova uma habilidade advinda da experiência do fotografo. É como se todo acontecimento estivesse resumido naquela imagem.

No restante da cena, que provavelmente foi organizada pelo fotografo, a pequena bailarina aparece sendo coordenada pelo professor da escola de samba, o Paulo da Portela, e ao mesmo tempo a assistida por Disney e sua comitiva. Estavam sentados no mesmo plano da pequena dançarina, posição que configurou uma imagem única. Trata-se de uma cena rara do cinema afro-latino. Basta ver nas imagens que podemos colher de forma rápida na internet sobre essa viagem de Disney pela América Latina, provavelmente a única imagem em que aparece a população negra, é consequência desses registros na quadra da Portela. Indicando a emergência das escolas de samba no campo das relações culturais brasileiras. Desta forma a imagem como linguagem problematiza um ângulo, pouco discutido na perspectiva racial, mais muito presente nas diretrizes que rondavam a política de Turismo do DIP.

A fotografia da bailarina do morro da Favela foi produzida num contexto de sociabilidade urbana de valorização do samba, do malandro, e de uma cultura popular que ganhou diversos planos interpretativos na chamada Política da Boa Vizinhança. Para além da imagem, sobretudo dimensionando os seus entornos de produção, não é difícil constatar o caráter "noturno" que circulava nas relações culturais, do raro enquadramento da população negra, e especialmente quando essas práticas se articulavam com algumas questões de política externa.

Jonh Berger (2013) sublinha que devermos compreender uma fotografia considerando o conteúdo invisível, chamando a nossa atenção menos para a forma, e sim para o tempo, no jogo entre ausência e presença. Desta forma as contradições do regime estão ali na imagem mediando pela tensão do ato de fotografar, selecionando cenários, ao mesmo tempo 
A MEMÓRIA FOTOGRÁFICA DE HOLLYWOOD EM MADUREIRA: EDITANDO POSES E

buscando afirmar a legitimidade de registrar um importante acontecimento num terreiro de escola de samba na década de 40. Embora já estivessem disponíveis muitas câmaras, técnicos e um produtor de Hollywood naquela noite em Madureira. Coube a veterana ferramenta da máquina de fotografar a função de produzir uma das primeiras narrativas das escolas de samba. Neste sentido, a fotografia funciona como a memória, impulsionada por práticas de edição, seleção e enquadramentos de seus objetos.

Para finalizar essa breve digressão, caberia perguntarmos qual o lugar de origem da pequena bailarina. Seria mesmo do morro da Favela? Não seria uma identificação produzida pelos jornalistas do jornal $O$ imparcial quando receberam a fotografia distribuída pelo DIP. Nas matérias publicadas pelos jornais Correio da Manhã, O Jornal e Diário Carioca, a pequena dançarina, que alguns classificaram com cerca de seis anos de idade, foi identificada como moradora do morro da Portela. No campo das representações o morro da Favela, hoje morro da Providência, localizado na região portuária do Rio de Janeiro, é lugar de memória para compressão do próprio samba e da história dos negros no Brasil. Enfim, a questão é que a presença de Walt Disney na Portela atraiu sambistas de diversos locais, e mesmo de simples admiradores de seus desenhos para um acontecimento em Madureira.

\section{Contextualizando a construção da memória fotográfica}

Uma parte importante da visita de Walt Disney ao Brasil, em 1941, foi coordenada pelo Setor de Turismo, que na época era vinculado ao Departamento Imprensa e Propaganda. Assim a sua presença na Escola de Samba Portela resultou num conjunto de fotografias. Algumas foram publicadas nos jornais, enquanto que outras imagens ficaram sob a guarda da antiga Agência Nacional, e posteriormente cedidas ao Arquivo Nacional. Em virtude do processo de digitalização foram recuperados alguns negativos produzidos no referido encontro, o que nos possibilita compreender na perspectiva da visualidade os detalhes deste importante acontecimento na trajetória das Escolas de samba.

\footnotetext{
${ }^{4} \mathrm{~A}$ fotografia em questão é derivada dos negativos da Agência Nacional.
} 
No circuito de Walt Disney pela América Latina ele coletou dados sobre as culturas locais. Em alguns países como Uruguai e Argentina foram produzidos documentários, os quais_fazem parte hoje de uma memória visual da diplomacia cultural do período da Segunda Guerra Mundial. Uma discussão que tem chamado a atenção de pesquisadores de diversos campos disciplinares. A música, os arquivos, as performances, os festivais e o próprio trânsito de artistas entre os países são temas que estão sendo abordados através de múltiplas perspectivas.

Embora a presença de Disney no Rio tenha sido no mês de agosto, o Setor de Turismo inseriu na agenda do ilustre visitante uma exposição de fotografias de Jean Manzon sobre a diversidade da cultura brasileira, sobretudo o carnaval. (Fig.2) A realidade é que o carnaval sempre foi um campo muito rico de produção de imagens. Debret celebrou em suas gravuras a herança do entrudo português, que tomou conta do carnaval no século XIX. As Grandes Sociedades se inspiravam no carnaval de Veneza, os confetes e flores evocavam as lembranças das tardes italianas.

Com a implantação da indústria fonográfica, o advento da música popular consolidou o samba e as marchinhas carnavalescas numa narrativa sobre os elementos da nacionalidade. Assim o surgimento e a popularização dos meios de comunicação de massa como o rádio, a música popular foi celebrada como ícone de exportação. A cantora Carmen Miranda tornou-se a embaixatriz do samba. Para FLECHET $(2013)^{5}$ as identidades nacionais estão vinculadas ao processo de produção cultural, ou seja, é interessante perceber as ações dos Estados Nacionais operando a música como instrumento de diplomacia cultural. Assim, sugerirmos que a fotografia em questão deriva desta dinâmica política e social. Coube um espaço comunicativo através das fotografias públicas, cuja função para sua legitimação era capturar traços de uma busca pela justiça social, integração social e luta antifascista.

A questão central que nos interessa problematizar neste artigo é a ambivalência da imagem produzida pelo DIP (Departamento de Imprensa e Propaganda), em 1941, no terreiro da Escola de Samba Portela (Fig.1). Assim, se por um lado a fotografia foi lembrada no sentido de representar as relações desiguais entre o Brasil e os Estados Unidos (TOTA, 2000, p.96).

${ }^{5}$ Para Anais Flechet a noção de diplomacia musical foi pouco explorada pelos pesquisadores. 
A MEMÓRIA FOTOGRÁFICA DE HOLLYWOOD EM MADUREIRA: EDITANDO POSES E

Numa outra abordagem é interessante pensar a produção da imagem como um contradiscurso das relações culturais no contexto de emergência dos regimes totalitários no mundo. MAUAD (2014) em seu estudo contextualizou uma geração de fotógrafos do pós-guerra, observando o sentido de engajamento social. Nesta perspectiva as imagens surgem como resultado de um processo de intertextualidade ao absorver formatos narrativos de outros contextos, elas são condicionadas por outras, mesmo produzidas em espaços e tempo diferentes. Caso contrário, o resultado disso tudo é um olhar saturado ideologicamente sob a imagem. Notificando um enquadramento do artefato imagético como apenas instrumento de propaganda oficial do Estado $\mathrm{Novo}^{6}$. Na realidade tal abordagem representa uma forma de classificação, e automaticamente uma desclassificação da fotografia, em busca de uma totalidade.

Assim, a fotografia da pequena bailarina deve ser compreendida como linguagem num contexto social muito complexo, na qual o regime político instrumentalizou o gênero musical samba, para demarca-lo como espaço da nacionalidade; mas abriu janelas interessantes nunca visualizados anteriormente. Neste sentido a própria produção da fotografia deve ser entendida como um acontecimento singular na História das Escolas de Samba. MCCANN (2004) ao discutir a emergência de sambistas importantes como Blecaute ${ }^{7}$ e Wilson Batista no universo radiofônico entre 1930 e 1950, mostrou que o samba foi utilizado tanto para apoiar como desmentir a retórica da democracia racial.

Numa abordagem interpretativa a ambivalência da imagem pode ser referendada como um sociograma capaz de articular a percepção da emergência das escolas de samba no âmbito das relações culturais. Além de sua função documento, ela assume, quando atravessa outras temporalidades, uma aderência de arte da memória. Sendo assim, é fundamental compreender a imagem a partir de uma percepção de aderências simbólicas, o que implica em pensa-la em sua capacidade de efetuar múltiplas ressignificações identitárias. (SILVA, 2011)

\footnotetext{
${ }^{6}$ Essa questão será aprofundada em reflexões futuras a partir da orientação de fotografia pública.

${ }^{7}$ Conhecido como o General da Banda, Otávio Henrique de Oliveira nasceu na cidade paulista de Pinhal em 05/12/19.
} 
Neste sentido, a fotografia assume uma dimensão de potência criativa em que a imaginação e a memória nos insere num processo de construção de imagens, ou seja, a construção social da imagem é fenômeno muito semelhante construção social da memória. (SILVA, 2011, p.229) A fotografia como coisa, um objeto material e ao mesmo tempo imaterial, funciona como um disparador de lembranças. Situando-se assim como mais um dos itinerários ${ }^{8}$ da memória. Por outro lado, estamos diante de uma nova fase em que as imagens derivadas de reprodução técnica se afirmaram pela complexidade de sua multiplicidade. Desta forma o arquivo(fig.1) que articulamos como artefato de memória não é o mesmo circulou nos jornais durante a política da boa Vizinhança, todavia essa condição do arquivo de sua duplicidade é capaz de produzir um efeito para que possamos ressignificar as origens de sua produção, encontrado os elos entre o seu passado e o presente e vasculhando os efeitos de sua circulação e produção como memória.

A perspectiva que considera os elementos da produção da fotografia trabalha articulada a uma instância marcada pela via criativa do pesquisador. Captando ações e sentidos, muitas vezes não percebíveis diretamente na imagem, mas que foram determinantes para a sua produção. Segundo (KOSSOY, 2001, p.143) a finalidade da produção do artefato fotográfico é um dos principais núcleos metodológicos das análises estéticas das fotografias. É neste sentido que a fotografia foco desta análise será abordada

\section{O poder das Agências "governamentais" na produção do imaginário.}

Conforme (DIDI-HUBERMAN, 2012, p.208): "não existe forma sem formação, e não existe imagem sem imaginação". Compreendemos que parte da ideia que resultou na produção da fotografia da bailarina do morro da Favela foi gestada em solo nacional, pelo Departamento de Imprensa e Propaganda; entretanto as suas impressões também estão ligadas ao contexto social mais amplo. Isto é, se faz necessário refletir que seu nascimento está vinculado a uma estrutura formada pelos objetivos da política externa da época, que ficou popularmente conhecida como a "Política da Boa da

${ }^{8} \mathrm{~A}$ ideia de itinerários históricos culturais deriva de uma dissertação de mestrado do ICOMOS -Conselho Internacional de Monumentos e Sítios. (BERND, MANGAN,2017). 
A MEMÓRIA FOTOGRÁFICA DE HOLLYWOOD EM MADUREIRA: EDITANDO POSES E

Vizinhança," do presidente Roosevelt para a América Latina. Tal política acentuou as relações entre o Brasil e os Estados Unidos no contexto da Segunda Guerra Mundial. Fizeram parte deste cenário imagético diversos elementos: as músicas de Ary Barroso, o samba, o Departamento de Imprensa e Propaganda, a CIAA de Nelson Rockfeller, Walt Disney, e, sobretudo, a emergência da cultura visual, em que a fotografia ganhou centralidade.

Em 1941, Walt Disney não era apenas mais um dos inúmeros ilustres visitantes que chegaram ao Brasil, em geral, por meio de navios que ancoravam no Cais do Porto carioca no intuito de conhecer a cidade do Rio de Janeiro. A sua viagem foi feita por avião. Disney tinha uma missão bem definida, que envolvia uma formulação de linguagem estética para toda América Latina, no sentido, de neutralizar o avanço do fascismo na região. (LOCHERRY, 2015).

Por outro lado, a imagem do Brasil estava inevitavelmente ligada ao imaginário projetado para o exterior na forma de "terra de samba e pandeiro", aliás muito bem lembrada no samba de Assis Valente: "Brasil pandeiro". Uma imagem construída nas primeiras décadas do século $\mathrm{XX}$, através do cancioneiro popular, articulada a um processo identitário do país repleto de contradições. Para um discurso que já gravitava nos limites da política de turismo essa imagem do Brasil representava um verdadeiro atraso ${ }^{9}$. Para os estrangeiros que desembarcavam aqui fugindo da guerra essa diferença guardava um tom de esperança em relação ao que acontecia na Europa.

A presença de Disney no Brasil durou cerca de três semanas, e sua presença na Portela passou por diversas mediações, antes de ocorrer de fato. Afinal o contexto da Segunda Guerra Mundial era um momento delicado, o país representava uma área estratégica por sua posição privilegiada no Atlântico Norte. Não fora coincidência que antes de chegar ao Rio, Disney passou por Natal, que posteriormente teve seu espaço cedido para instalação da base americana.

O envolvimento forçado do Brasil na guerra se desenvolveu com muita negociação nos bastidores. Segundo DUMONT (2014) naquela conjuntura, não havia ainda uma burocracia de política exterior completamente sistematizada, o que configurava um conjunto de relações

${ }^{9}$ Neste campo do Pensamento Social brasileiro reúne uma diversidade autores a partir do fim do século XIX. 
político-administrativas em torno de figuras centrais que atuavam no DIP (Departamento de Imprensa e Propaganda). Especialmente na figura de Lourival Fontes, cujo acompanhamento das atividades culturais, já realizava anteriormente. Em 1933, ele já era percebido pela imprensa carioca como uma espécie de controlador-mor do setor do turismo do Distrito Federal. (SILVA,2018)

Com a criação do DIP, em 1939, sua função foi ampliada. As funções atinentes à censura cinematográfica contaram com a participação de personalidades do então Ministério do Exterior. Tal aspecto configurou uma mistura de funções burocráticas que contextualizam o momento de envolvimento do país com a guerra. Ou seja, o país se organizou administrativamente muito em função das emergências de um tenso contexto internacional. O cinema atuaria como forma de mediação.

No mesmo ano, no glamoroso cassino da Urca, o dramaturgo norteamericano Marc Connelly presenciou a apresentação da cantora Carmen Miranda. Naquela oportunidade a exuberância de sua performance conquistou a atenção do empresário Lee Schubert. Era a descoberta da "pequena notável". A consequência deste encontro resultou em um contrato com a cantora, que teve inclusive chancela do cônsul norte americano no Rio. Carmen Miranda se tornava uma artista exclusiva da Select_Operating Corporation, o que lhe garantia espaço de atuação em locais exclusivos do grupo. Surgia a embaixatriz do samba que significou basicamente no estreitamento das relações entre os dois países.

Foi a própria cantora que estilizou um traje típico das baianas, e assim tornando-se a artista mais conhecida no exterior. A dança em sintonia com a música ocupou um espaço muito particular nas diversas nacionalidades. Portanto se os Estados Unidos tinham o foxtrote, Cuba a rumba, o Brasil, que em outro contexto era terra do maxixe, agora aparecia com o samba. MENDONÇA (1999) observou que Carmen Miranda assinou o seu contrato em 1939, e partiu neste mesmo ano para se consolidar como a grande divulgadora do samba.

Através dessas relações se esboçava a estratégia de construção de uma linguagem para a América Latina, que ganhou contornos mais definidos na Feira Mundial de Nova York, cujo homenageado foi o Brasil. Naquela oportunidade os organizadores da feira dedicaram um espaço exclusivo com 
A MEMÓRIA FOTOGRÁFICA DE HOLLYWOOD EM MADUREIRA: EDITANDO POSES E

as cores verde e amarela, projetado por Lucio Costa e Niemeyer. A inauguração se deu no mês de abril, alcançando um público de 44 milhões de pessoas, em 4 meses. No campo tecnológico, uma das novidades apresentadas foram as fotografias em cores para o consumo em grande escala, e as luzes fluorescentes. (TOTA, 2000).

Segundo (JUNIOR, 2017, p.131), Carmen Miranda se apresentou na feira representando o Brasil, sob a supervisão do Departamento de Imprensa e Propaganda, dado que situa a esfera de atuação do órgão para além das fronteiras nacionais. A principal função da agência governamental era cuidar da imagem do país. Nesta época o DIP selecionava ativistas e artistas que formulassem uma perspectiva ideológica favorável ao regime. O órgão era diretamente ligado à presidência da República, e exerceu diversas ações no campo das relações culturais, sobretudo, através do financiamento de turnês de artistas.

Contextualizando a época, Correa (2000, p.261) destaca o caso de uma fotógrafa norte-americana que teve seu trabalho recusado durante a realização da feira de Nova York. A razão da censura foi em virtude do trabalho ter como temática a exposição da população negra brasileira durante o carnaval. Naquela oportunidade, o representante da CIAA justificou a censura argumentando a posição do governo brasileiro, que naquela conjuntura, evitava a autorização de filmes mostrando muitas pessoas negras. Há muito mais no Brasil que saculejos de negros, negros no carnaval, instituições religiosas e bricabraque". (Apud. CORREIA, 2000, p.261)

Tais elementos mostram os fragmentos da formação dos "agenciamentos" no campo das relações culturais entre Brasil e Estados Unidos, mediados pelas agências governamentais._Percebe-se que, de acordo com os interesses em questão, eles se complementavam, absorvendo possíveis divergências de grupos internos, em função de questões estratégicas articuladas sob a órbita dos Estados Nacionais. O que demonstra também os limites identitários dessas "fronteiras" permeadas por disputas, negociações, silêncios, tudo isso produzindo memória como uma espécie de "imagem ausente'. (GOMES e VIEIRA,2016)

Sendo assim através do artefato fotográfico da bailarina do morro da favela notificamos a percepção de algumas zonas sóbrias que atuaram assessorando o imaginário nos setores da política externa daquela época. BOEHN (2015, p.32) em sua reflexão sobre o lugar das imagens observa que a 
imagicidade $^{10}$ nada depende do objeto representado. Elas evocam como elementos ausentes na imagem, recortados e editados, mas ao mesmo tempo presente. Neste sentido a memória assim como a fotografia assume formas de edição e seleção. A percepção da fotografia, sob uma proposta reflexiva, não pode ser analisada desconsiderando o contexto social na qual está inscrita e nasce. É necessário compreender o processo de produção e circulação, sobretudo pela sua singularidade em registrar o negro nas relações culturais, em conjunto com o sistema de valores dos agentes que disputavam direção da política de turismo da época. Em que modernizar implicava na cultura do corte e edição da memória africana.

\section{Os cenários do "samba” para Disney}

Os registros de imagens sobre a presença de Disney no Brasil em 1941 são extensos. Afinal sua presença no Rio serviu também para a divulgação de pontos turísticos da cidade. As reportagens de jornais e revistas evidenciavam grande expectativa sobre a visita. Antes mesmo de sua chegada em terras brasileiras, a vinda de figura tão marcante já se configurava como um acontecimento. Foi neste clima que aconteceram as primeiras exibições do filme Fantasia para uma exclusiva e seleta audiência no navio Argentina, ancorado no cais do porto carioca. Ali estiveram presentes diversas autoridades, entre elas Lourival Fontes, diretor do DIP, Israel Souto, diretor de cinema e teatro, e Assis de Figueiredo, diretor de turismo.

A recepção de Disney foi organizada com honras de chefe de Estado. Contou com a participação de quase todo alto escalão do governo de Getúlio Vargas: de gente como Oswaldo Aranha à primeira dama Darcy Vargas. Tal produção não escondeu que o objetivo central do filme era apenas uma plataforma para encobrir o lado político e estratégico de sua atuação como embaixador da "Política da Boa Vizinhança". (KAUFMAN,2009, apud. ROSA, 2010). Os encontros com autoridades brasileiras, intelectuais, reuniões e visitas aos pontos turísticos da cidade resultaram num campo muito rico de

\footnotetext{
10 Imagicidade não depende em nada do objeto representado. As imagens não são simples representações demonstrativas de uma significação já construídas em outro lugar, são, ao contrário,mostrações originarias.(BOEHM,2015,p.32)
} 
A MEMÓRIA FOTOGRÁFICA DE HOLLYWOOD EM MADUREIRA: EDITANDO POSES E

imagens sobre um Brasil moderno que o regime desejava projetar, com destaque para as praias da Zona Sul da cidade.

Sempre acompanhado por membros do Departamento de Imprensa e Propaganda, em uma das atividades, Disney assistiu uma apresentação de músicos brasileiros. Foi no dia 21 de agosto, no período da tarde, nos estúdios da tradicional Radio Club do Brasil. A apresentação ficou a cargo da orquestra PRE-8, sob a responsabilidade de Romeu Ghispmann, e um dueto de cantores formados por Paulo Tapajós e Nuno Roland. O Correio da Manhã classificou o evento como: "Os sambas para Disney". No repertório: "Aquarela do Brasil”, de Ary Barroso; "Rancho fundo", também de Ary Barroso, em parceria com Lamartine Babo; "Ritmo de samba na cidade", de Luciano Perrone; "Onde o céu é mais azul”, de João de Barro; Aberto Ribeiro e Alcyr Pires Vermelho e o clássico do folclore nacional "Meu limão meu limoeiro". Ao final da apresentação Disney não esqueceu de elogiar "Aquarela do Brasil", classificando-a como "admirável". Segundo o mesmo jornal, após a apresentação dos músicos, Disney subiu ao palco, e assistido pelo então diretor de turismo Assis de Figueiredo, examinou os detalhes de alguns instrumentos: o reco-reco, o tamborim e o chocalho. Tais instrumentos foram incorporados na composição instrumental dos conjuntos regionais, e exerciam sua primazia durante as performances das escolas de samba. Foi uma época em que os instrumentos de percussão ganharam visibilidade no rádio, advindo de uma longa tradição nas festas carnavalescas, mas que se tornaram ícone na emergência das escolas de samba. (CORREIO DA MANHÃ, 26 de agosto de 1941 p.13). 

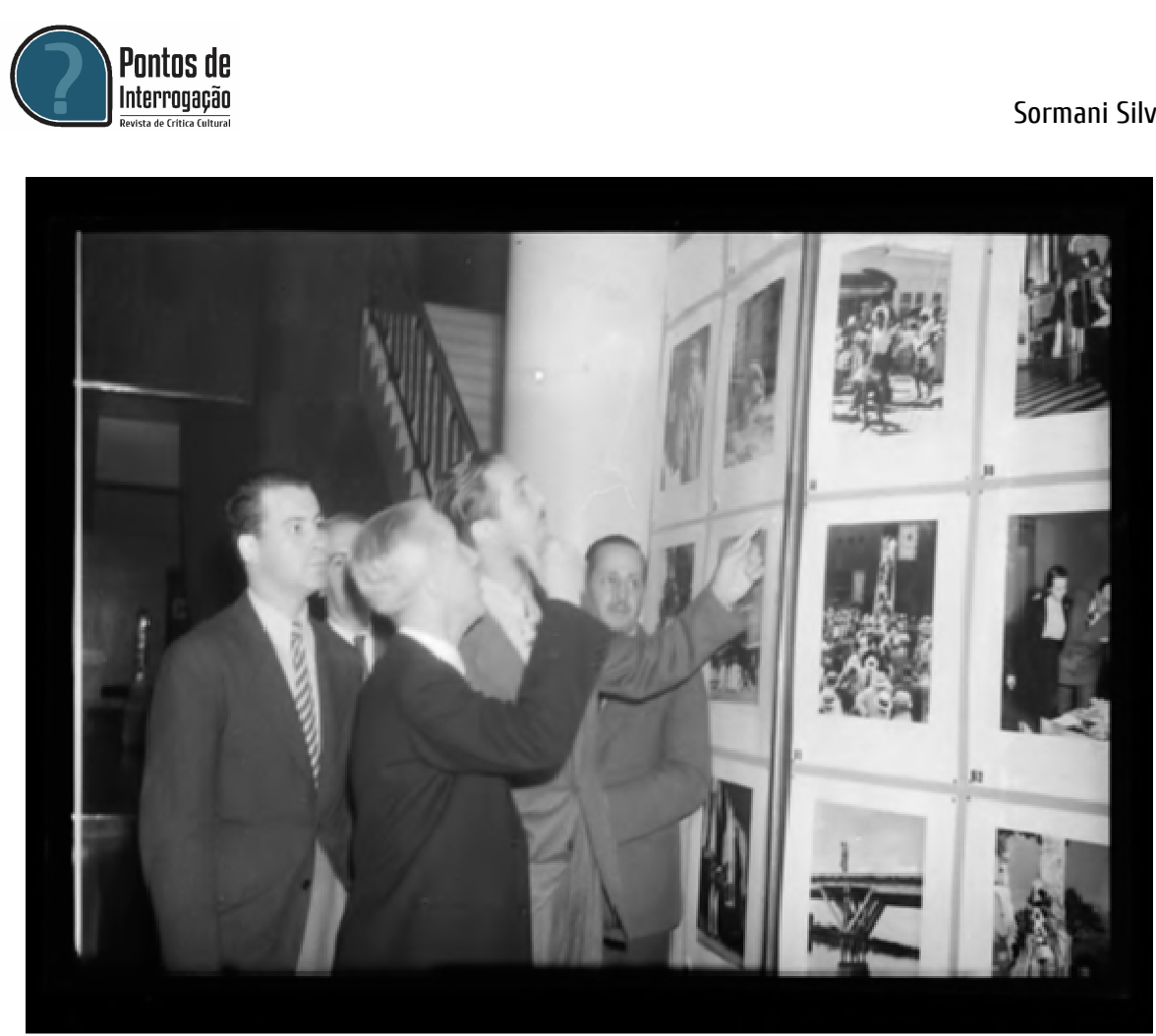

Fig. 2 fotografias do SNI -Fundos e coleções: Arquivo Nacional-fotografia de Disney na ABI, ao centro, à esquerda o fotografo Jean Manzon e no fundo Assis de Figueiredo, diretor de Turismo

Como sugere a imagem (fig.2), a passagem de Disney pelos países da América Latina foi dotada de um tom de trabalho de campo para seus filmes. A fotografia se refere a um dos momentos da coletiva de imprensa, em que foi recepcionado no dia 18 de agosto de 1941, no Rio. Pode-se perceber a atenção que o artista deu ao ser apresentado, durante uma exposição de fotografias, para uma imagem que no alto da parede, que retratava um grupo de foliões de rua. Provavelmente dançando o frevo pernambucano, que aliás foi introduzido no Rio de Janeiro em 1935, pelo comerciante Vitorino Rios. Os clubes de frevo tiveram durante muito tempo um papel de destaque, inclusive desfilando na mesma passarela das escolas de samba. A imagem também apresentou alguns pontos turísticos, os quais Disney incluiu em sua agenda, todavia a imagem do carnaval parece ter aguçado sua atenção, o que ratifica um dos objetivos de sua viagem em conhecer alguns elementos do carnaval brasileiro.

A visita também teve alguns contratempos envolvendo membros de sua comitiva, os quais cometeram algumas "gafes", mas com sensibilidade soube contornar a situação. Disney conseguiu persuadir as autoridades do 
A MEMÓRIA FOTOGRÁFICA DE HOLLYWOOD EM MADUREIRA: EDITANDO POSES E

Setor de turismo para que o conduzisse ao espaço das escolas de samba. Sendo assim obteve o triunfo de visitar um terreiro de escola de samba, de forma singular para a época, pois contou com bom suporte do DIP (Departamento de Imprensa e Propaganda). Trata-se de um registro imagético raro, pois como veremos mais adiante, a cobertura jornalística abordou a existência de um terreiro de escola de samba como algo desconhecido, até mesmo para a maior parte da população da cidade.

$\mathrm{Na}$ época era bem nítido um tipo de samba que dominava o universo radiofônico. Geralmente composto por artistas derivados dos extratos sociais de classe média. A oficialização das festividades do carnaval de 1932 foi o grande acontecimento do período. As escolas de samba que tinham sido recentemente incorporadas ao calendário oficial da cidade, pelo Prefeito Pedro Ernesto, eram identificadas através de seus baluartes: Paulo da Portela, na antiga Vai como Pode; Cartola, na Estação Primeira de Mangueira; Mano Elói, na Deixa Malhar; Antenor Gargalhada, da Azul e Branco do morro do Salgueiro, e toda uma série de sambistas que foram nomeados cidadãos do samba.

A ideia de Cidadão Samba, criada no ano 1936, em oposição a figura do Rei Momo e do Cidadão Momo"1 , talvez seja a primeira configuração de identificação dos sambistas das escolas de samba no plano das relações culturais. A proposta acolhia a função de autenticidade, promovendo um saber popular que seria transmitido entre as gerações, que demarcava também uma memória visual através da fotografia. O interessante é que a ideia surge no contexto de emergência de uma nova logística da percepção que se desenvolvia nas ondas do rádio, que diferentemente do teatro de revista, música e performance; o rádio facultava a descontinuidade do campo de visão entre o emissor e o receptor da mensagem. Assim, as narrativas de autenticidade do samba de morro interagiam com essas novas formas de percepção.

Paulo Portela, que participou deste evento organizado pelo DIP, ao lado de Heitor dos Prazeres e Cartola, já estava na escola de samba Lira do Amor. Um dos motivos de sua saída da Portela foi em virtude de alguns

\footnotetext{
${ }^{11}$ Ver In: SILVA, Sormani da. Escola de Samba Deixa Malhar: Batuques e outras sociabilidades no tempo de Mano Elói na Chácara do Vintém entre 1934 e 1947, Dissertação de Mestrado -PPRER- CEFET: RJ, 2014.
} 
dirigentes impedirem a entrada de Heitor do Prazeres no desfile da Portela. Paulo da Portela entendeu o acontecimento como uma desfeita pessoal, e abandonou a sua agremiação de coração, o compositor foi cidadão momo, cidadão samba, e era um dos principais nomes do conjunto das Escolas de Samba. A sua imagem registrada em diversas fotografias durante o evento pode ser visualizada sob vários ângulos, o que mostra a sua interação com a produção de imagens, envolvendo técnicos, fotógrafos e demais participantes do evento.

Nos resta saber alguns detalhes desse encontro, realizado em Madureira. O setor de turismo, depois do evento nos Estúdios da Rádio Club, teve apenas cinco dias para organizar a recepção de Walt Disney, tendo como mediadores os sambistas da Portela. No dia 25 de agosto, data de celebração do Dia do Soldado, foi a solução encontrada para atender às pretensões do ilustre visitante.

Desta forma sob a supervisão do DIP (Departamento de Imprensa e Propaganda) foram garantidos os protocolos de censura e segurança nacional para o evento. Para isso foi delimitado que os registros das imagens se resumissem ao período noturno, aspecto que limitou o campo de visão das fotografias. Não podemos esquecer que a guerra ${ }^{12}$ e a produção de imagens, por meio do cinema ou da fotografia, estão em alguma medida interligadas, processo que permite observar o triunfo da imagem sobre o objeto, sobre o fato, lembrando as análises de Paul Virilio, em seu clássico "A máquina de Visão" (1988) e outros.

\section{Hollywood em Madureira: Disney em uma noite de batucada na Portela}

A comitiva de Disney saiu do Copacabana Palace às 17:00 horas, em direção à Escola de Samba Portela, com uma rápida passagem no morro do Salgueiro, sobre as qual não temos registro visual. Cabe lembrar que determinados aspectos podem parecer meros detalhes de narrativa, mas informam o controle e limitação da produção de imagens nos ambientes internos (privados) das visitas. As condições de produção desses arquivos

${ }^{12}$ A questão da neutralidade na guerra neste momento ainda era saída deseja por vários setores da sociedade brasileira, sobretudo pela questão econômica. 
A MEMÓRIA FOTOGRÁFICA DE HOLLYWOOD EM MADUREIRA: EDITANDO POSES E

foram condicionadas pela questão de segurança interna, sobretudo por ocorrer no contexto da Segunda Guerra Mundial. Tratava-se de uma política de controle governamental sobre o processo de circulação de imagens do território brasileiro para o mundo. Naquela conjuntura as possíveis consequências de usos dos artefatos visuais para fins de estratégia militar eram plenamente compreensíveis,_fato que condicionou a produção da fotografia. (fig.1)

Coube a Assis de Figueiredo, diretor de Turismo, a chefia da comitiva que levou Disney ao terreiro ${ }^{13}$ da Portela. Cabe lembrar que o Departamento de Imprensa e Propaganda já havia patrocinado um evento semelhante no morro da Mangueira. Este, tendo o samba como suporte, foi transmitido diretamente para a Alemanha como parte do programa $A$ Hora do Brasil, reforçando assim as relações bilaterais com o país europeu. Mas infelizmente deste evento não temos nenhum artefato imagético.

Não é possível inferir num breve artigo todos os elementos que pautaram a presença de Disney no Brasil. A ideia de transformá-lo embaixador da política da boa vizinhança, como representante do governo norte-americano, foi o guarda-chuva principal. Um projeto que muitos atribuem a John Jay Whitney, o diretor de divisão cinematográfica da Coordination_of Inter-American Affairs (Coordenação de Assuntos Interamericanos). Segundo Eliot (1995, p.189), a questão da jornada da "boa vontade" foi parte de uma estratégia elaborada por Roy, o irmão que cuidava dos negócios de Disney. O objetivo era tirá-lo do centro das atenções, em virtude de uma greve de funcionários que acontecia em sua empresa. Walt Disney na época estava profundamente abatido pela crise financeira que alcançava os seus negócios. Assim, depois de relutar em abandonar sua empresa no ápice de uma crise, um acordo com o governo lhe garantiu a quantia de USS 100 mil para produção de dois filmes durante a viagem. Por outro lado, a publicidade positiva como embaixador da "boa vontade" diminuía os boatos de simpatizante do nazismo derivada de sua participação nos comícios da "America First", em Nova York. A realidade é que naquele

\footnotetext{
13 Muniz Sodré percebe a importância desses espaços em consequência do processo escravagista que destruí as organizações sociais do povo negro. No terreiro a reconstituição de linhagens era um ato político de repatrimonialização. SODRÉ, Muniz. O terreiro de a cidade: A forma social negra brasileira. Salvador: Imago. 2002
} 
contexto social, qualquer opinião contrária à participação na guerra, o indivíduo era diretamente envolvido como um simpatizante do Eixo (ELIOT, 1995, p. 190).

Em outra instância, a viagem de Disney entrou nos planos de Roosevelt no sentido de neutralizar a forte influência da Alemanha no governo de Getúlio Vargas. Uma simpatia que se articulava para além dos negócios. Movia-se na estrutura de governo, aliás dentro daquilo que Gerson Moura (1984) qualificou como o jogo duplo de Getúlio: de um lado flertando com os americanos; e de outro com Alemães, até quando os navios brasileiros começaram a ser abatidos pelas forças do eixo. Neste caso, a fotografia (Fig.1) pode ser vista como uma produção imagética voltada para a construção do imaginário da democracia racial, que entre as décadas de 1960 e 1970, passará por sérios questionamentos. Naquele contexto, em que o mundo lutava contra os horrores do fascismo, a imagem possuía uma função discursiva de promoção da ideia de que o Brasil oferecia ao mundo uma narrativa singular.

$O$ fato é que a imagem passou por um processo de congelamento nas décadas seguintes. Foi esquecida e recebeu outras aderências simbólicas (SILVA, 2016) e, portanto, diluída de capacidade de engajamento no pós-guerra, sendo praticamente ignorada pelos pesquisadores. Todavia na época em que a imagem foi produzida e colocada em circulação, entre 1941 e 1946, a fotografia possuía uma capacidade de engajamento numa perspectiva que captava um horizonte de expectativas de afirmação de uma cultura autêntica das escolas de samba, que se articulava com a nascente indústria do turismo.

A emergência de sambistas nos programas de rádio, como Geraldo Pereira e Wilson Batista, não derivou apenas de propaganda, sinalizou sim, como lembrou (MCCANN, 2004) algumas janelas de oportunidades no contexto da Era Vargas. No entanto, voltando à presença de Disney na Portela, é interessante lembrar que a mesma teve grande repercussão na imprensa carioca. O jornal O Imparcial foi o matutino que produziu a mais ampla cobertura do acontecimento. Divulgou uma matéria sob o título: "Quando Walt Disney caiu no samba":

“Não pretendemos descrever aqui, minúcia a minúcia, o que foi a visita de Walt Disney e seus colaboradores a um terreiro. O terreiro todos devem saber como é. E os que não souberem e não quiserem ir ver de perto, que esperem os futuros desenhos animados. Walt Disney foi à 
A MEMÓRIA FOTOGRÁFICA DE HOLLYWOOD EM MADUREIRA: EDITANDO POSES E FLAGRANTES DA BAILARINA DO MORRO DA FAVELA NO CONTEXTO DA "POLITICA DA BOA VIZINHANÇA"

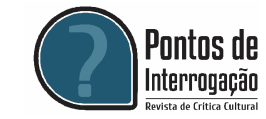

batucada pra ver como é, e traçar no celuloide. Não sabemos o que Walt Disney pensou ao ver aquele mundão de pastoras gingando e cantando "tiradas" por Paulo da Portela, no "Pai divino" que promete um céu que não é azul para os "colored” yankees. O que sabemos é que Walt Disney "caiu” no samba. Não gingou como as pastoras nem cantou. Mas ficou preso à magia do espetáculo, observando em detalhes e, três horas de-pois de estar assistindo à batucada, não queria sair da Escola do Portela. Mas os carros lustrosos buzinavam lá fora. Eram 21 horas. Walt Disney saiu, olhando para trás, para ver mais um pouquinho (JORNAL O IMPARCIAL 26/08/1941).

Como sabemos, o otimismo da matéria não foi completamente correspondido. Disney através da figura popularizada do Zé Carioca se adequou à narrativa hegemônica da identidade nacional. Hoje compreendemos que o horizonte de possibilidades, sinalizado na parte do trabalho que descrevemos os cenários para Disney, estava profundamente delineado dentro daquilo Bourdieu (1979) articulou como campo cultural, ou seja, quando se formulam um conjunto de regras visando o estabelecimento de relações de poder entre os demais grupos. As regras que organizam o mundo social são as mesmas que definem o que pode ser fotografável ou não, além de circular no meio social livre dos constrangimentos da ordem social. Desta forma a completa ausência de imagens de negros nos filmes de Disney, especialmente Alô Amigos, produzido ainda em 1942, pode ser um fator derivado de um espirito ${ }^{14}$ da política de turismo do DIP marcado por diversas formas de enquadramento das manifestações culturais. E isso se refletiu sobre um modo de olhar o país no exterior:

A visita de Disney foi um enorme sucesso, e não apenas com os brasileiros .Mas tarde, ele criou um personagem brasileiro, Zé Carioca, que - em um curta-metragem lançado pela Disney em 1943 - levou Pato Donald para uma viagem imaginária para conhecer o Rio de Janeiro e outras partes do Brasil. Tais desenhos se tornaram muito populares entre o público americano, apesar do fato de

\footnotetext{
14 Essa expressão Política do espirito é de Antómio Ferro, foi o mais representativo Secretario de Propaganda Nacional de Portugal. Suas ideias circularam com significativa no Brasil de Getúlio Vargas. CADAVEZ Cândida. A bem da nação: as representações turísticas no Estado Novo entre 1933 e 1940. Edições 70. Lisboa,2017.
} 
(como alguns críticos mais tarde destacaram) não contarem com personagens negros - uma omissão importante dada a marcante diversidade racial do Brasil (LOCHERRY,2015, p.123)

Assim é complexo articular de forma linear a emergência do gênero musical como produto de exportação, em concomitância com a não valorização de uma estética identitária negra e africana. Neste sentido, o artefato fotográfico do tipo da "bailarina do morro da Favela" funciona como uma espécie de cinza, um rastro. Didi-Huberman (2012, p.211) destaca que o arquivo é cinza no sentido de dar conta daquilo que o rodeava, e, portanto, ardeu. E sendo assim ao profanar a memória do fogo, das folhas que não arderam é que contatamos as experiências. A fotografia se instala como uma imagem que arde diante das narrativas sobre os limites da formação da identidade nacional. Anunciando aqui um dado mais enigmático, afinal o experimento fotográfico tem a capacidade de registrar um acontecimento em sua singularidade. Temos em tela o registro do uso das imagens das escolas de samba no campo das relações culturais. A fotografia, neste caso, assume a função de foto testemunho de um acontecimento. Na terça feira, após o evento aqui analisado, a coluna Radio, do Jornal Amanhã, comentou positivamente a perfeita performance de Paulo da Portela. Chamou atenção das autoridades no sentido de criarem uma estrutura mais adequada para que as escolas de samba recebessem um visitante ilustre como Walt Disney. Afinal, segundo a reportagem, o mesmo não estava ali em busca de mero exotismo, e sim em pleno trabalho.

O curioso é que essas considerações, a priori até compreensíveis, no que concerne às normas da boa etiqueta, silenciam ${ }^{15}$ sobre os anos de convivência desses grupos no ambiente urbano do Rio de Janeiro através das grandes sociedades carnavalescas, nos ranchos e clubes sociais, que desaguaram na formação das escolas de samba na década de 20. A performance ${ }^{16}$ de Paulo da Portela, conforme a imagem fotográfica, é fruto de

\footnotetext{
${ }^{15}$ A fundação da União das Escolas de Samba, em 1934, em que Paulo da Portela também participou, derivou do programa de desenvolvimento do turismo internacional na Administração do Prefeito Pedro Ernesto, que instituiu a Diretoria Geral de Turismo.

${ }^{16}$ Muniz Sodré também busca referências no campo da diáspora com as práticas culturais da cultura negra norte americana, no caso especial com os músicos de jazz. (SODRÉ,2002).
} 
A MEMÓRIA FOTOGRÁFICA DE HOLLYWOOD EM MADUREIRA: EDITANDO POSES E

experiências iniciadas por Sinhô, e outros sambistas de sua época, cujos trabalhos nunca ficaram ajustados_plenamente ao circuito das narrativas do Estado-Nação.

\section{Conclusão}

Este artigo, mesmo que de forma preliminar, buscou situar alguns elementos do processo de produção da fotografia da bailarina do morro da Favela, por meio de uma proposta reflexiva sobre a imagem. Inserindo uma abordagem que envolve diversos autores, mas que se articulam pela via que explora o potencial criativo na compreensão dos arquivos fotográficos. Assim, formulamos uma memória através da fotografia. (KOSSOY,2001; SILVA,2011; DIDI-HUBERMAN,2012).

Procuramos contextualizar que a produção do artefato imagético contou com a colaboração de diversos agentes, e que deve ser ressignificado a partir da dinâmica conceitual de uma fotografia produzida pela Divisão de Turismo, que naquele contexto modernizou seu departamento de fotografia e cinema, estimulando a produção de uma linguagem fotográfica, que não se limitasse ao papel meramente informativo. Neste sentido, a imagem derivou de uma cultura política (MAUAD,2013) que transitou pelas agências de propaganda no contexto da Segunda Guerra Mundial, em que as imagens funcionaram como instrumento nas relações culturais ao promover visões de mundo e espacialidades.

Discutimos também que a fotografia deve ser imaginada como acontecimento, afinal foi produzida num momento em que o DIP possuía em seu quadro de pessoal, o fotografo que inventou o fotojornalismo no Brasil: o francês Jean Manzon. Se de um lado, neste momento da pesquisa, não é razoável determinar que o mesmo tenha sido o autor da fotografia. (fig. 1) Uma coisa podemos confirmar, ou seja, a imagem nasce quando o fotografo estava na condição de diretor do referido órgão.

Através da contextualização da imagem na perspectiva da ausência da população negra. Destacamos que a presença de Walt Disney no Brasil, em 1941, situou-se para além da premissa de divulgação de seu filme Fantasia. Estava em questão uma fase importante da carreira de Walt Disney, sobretudo em relação aos seus negócios, tangenciando as relações bilaterais entre os representantes da CIAA no Brasil, e o DIP (Departamento de Imprensa 
e Propaganda) na conformação de uma "imagem idealizada" do Brasil no exterior.

Enfim, nota-se a singularidade que possibilitou o registro inédito no terreiro da Escola de Samba Portela, como um dos empreendimentos mais badalados na época. É importante destacar que a função de receber autoridades e artistas, foi uma norma instituída no interior do DIP, e executada pela Divisão de Turismo, cuja lógica era a realização da propaganda do regime, e do país no exterior. Sendo assim, as imagens fotográficas cumpriram a missão de disputa na construção do imaginário sobre o Brasil. Ao tecermos sobre os itinerários deste arquivo como rastro de uma fotografia histórica, foi a oportunidade de conhecermos metaforicamente o verso da fotografia da bailarina do morro da Favela, aquilo que não foi impresso e continua até o momento indeterminado numa cena famosa. A fotografia, assim como a memória, é fruto de corte e edição.

\section{Referências}

ANDREWS, George Reid. América Afro-Latina (1800-2000). São Carlos, SP: EdUFSCar, 2007.

BERND, Zila.MANGAN, Patrícia Kayser Vargas. Dicionário de expressões da memória social e da cibercultura. Rio Grande do Sul:Ed. Unilasalle,2017.

BOEHM,Gottfried. Aquilo que se mostra. Sobre a diferença icônica. In: Pensar a Imagem. Emmanuel Alloa. Belo horizonte: Autêntica Editora,2015.

BOURDIEU, Pierre. La fotografia:um arte intermédio. México, Nueva Imagem,1979.

CORRÊA, Mariza. O mistério dos orixás e das bonecas: raça e gênero na antropologia brasileira, Lisboa :Revista Etnográfica, Vol. IV (2), 2000, pp. 233265.

DIDI-HUBERMAN, Quando as imagens tocam o real. Pós:Belo Horizonte, v 2, n. 4, p.204-219, nov.2012.

DUMONT, J. ;FLECHET, A. “Pelo que é nosso!": a diplomacia cultural brasileira no século $X X$ : Revista Brasileira de História. São Paulo, v. 34, № 67, p. 203-221 $-2014$.

ELIOT, Marc.Walt Disney: o príncipe sombrio de hollyhood. São Paulo: Marco Zero,1995. 
A MEMÓRIA FOTOGRÁFICA DE HOLLYWOOD EM MADUREIRA: EDITANDO POSES E FLAGRANTES DA BAILARINA DO MORRO DA FAVELA NO CONTEXTO DA "POLITICA DA BOA VIZINHANÇA"

GOMES, Edlaine C. e VIERA, Andreia L. da C. Novos contextos, antigas questões de memória. Morpheus: revista de estudos interdisciplinares em memória social. Rio de Janeiro, v.9. n15, 2016.

JUNIOR, Gonçalo. Pra que mentir? Vadico, Noel Rosa e o samba, São Paulo: Editora Noir, 2017.

LOCHERRY, Neill, Brasil: os frutos da guerra. Rio de Janeiro: Editora Intrínseca, 2015.

MAUAD, Ana Maria. Fotografia e a cultura política nos tempos da política da Boa Vizinhança: Anais do Museu Paulista: São Paulo: v 22, n1 p. 133-159. Jan jun. 2014.

Fotografia pública e cultura do visual, em perspectiva histórica. Revista Brasileira de História da Mídia, v.2, n.2,2013.

MENDONÇA, Ana Rita, 1999, Carmen Miranda foi a Washington, Rio de Janeiro, Editora Record.

MCCANN, Bryan. Hello, Hello Brazil: popular music in the making of modern Brazil, Duke University press Durham e London 2004.

MOURA, Gerson. Tio Sam chega ao Brasil: A penetração cultural americana. São Paulo: Editora Brasiliense,1984.

ROSA, Marli.Pato Donald no batuque dos "bons Amigos":Manifestações culturais na política da "Boa vizinhança", $2010 . \quad$ Disponível em:http://anphlac.fflch.usp.br/sites/anphlac.fflch.usp.br/files/marli_rosa.p df Disponível em 10/05/2018 http://anphlac.fflch.usp.br/sites/anphlac.fflch.usp.br/files/marli_rosa.pdf.

SILVA, Sergio.L.P.da. A fotografia e o processo de construção social da memória.in: Ciências Sociais Unisinos, São Leopoldo, Vol.47, n.3, p228-231, set 2011. ND

SILVA, Sergio.L.P. da e PIRES, Maria da Conceição Francisca. Fotografia e aderência simbólica: "aura" engajamento" e "memória" no protagonismo fotografico.in: Ciências Sociais Unisinos, São Leopoldo, Vol.52, n.3, p.437-446, set 2016.

TOTA, Antônio Pedro. O Imperialismo sedutor. São Paulo: Companhia das Letras, 2000.

KOSSOY, Boris, Fotografia \& História. São Paulo: Ateliê Editorial, 2001. 
BERGER, John, Compreender uma fotografia, In: TRACHETENBERG, Alan (ed.). Classic Essays on Photography. New Haven: Leete's Island Books, 1980, p. 317-320.

VIRILIO, Paul. A máquina de visão. Rio de Janeiro: José Olympio Editora, 1988.

Recebido em: 31/10/2018

Aprovado em: 04/12/2018 